\title{
Program pemberdayaan PKK melalui program pengembangan sistem akuaponik di Desa Ampeldento, Karangploso, Malang
}

\section{Asus Maizar Suryanto Hertika ${ }^{\mathbb{D} *}$, Mohamad Fadjar ${ }^{(\mathbb{D})}$, Setya Widi Ayuning Permanasari ${ }^{(\mathbb{D})}$, \& Bimo Aji Nugroho}

Fakultas Perikanan dan IImu Kelautan, Universitas Brawijaya, Indonesia

\section{*asusmaizar@ub.ac.id}

\begin{abstract}
PKK (Family Welfare Empowerment) group in Ampeldento Village is a community group whose role needs to be increased, especially in improving family welfare. The problem they have is that the PKK group does not understand the potential of the narrow land owned by the family is the potential to increase family nutrition through the development of aquaponic cultivation systems. Therefore, carried out the implementation of community service programs through the development of the aquaponics system. Data collection techniques are done through interviews and questionnaires. Evaluation of community understanding of the program was carried out using pre-test and post-test. Based on the results of questionnaires and interviews before the program's implementation, it was found that $70 \%$ of respondents did not know aquaponics, 50\% were not interested, 35\% were hesitant in developing aquaponics independently and $45 \%$ doubted aquaponics could improve people's welfare. Results improved significantly after the program's implementation and were inversely proportional, with $95 \%$ of the community believing that aquaponics could improve welfare and $70 \%$ of respondents wanted to develop it independently. Respondents stated that vegetables produced are faster growing, tasty, green, nutritious and large.
\end{abstract}

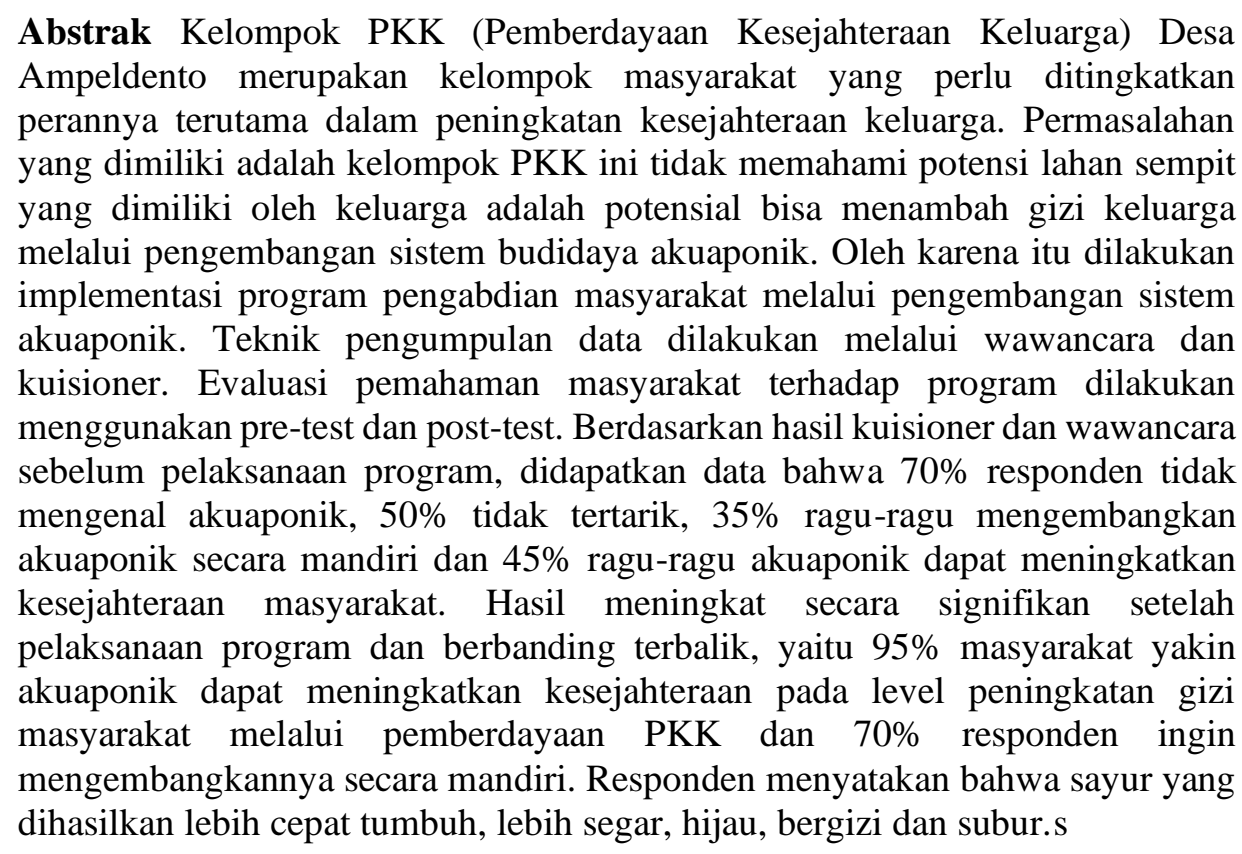

\section{¿ OPEN ACCESS}

Citation: Hertika, A. M. S., M. Fadjar., S. W. A. Permanasari., \& B. A. Nugroho. (2021). Program pemberdayaan PKK melalui program pengembangan sistem akuaponik di Desa Ampeldento, Karangploso, Malang. Riau Journal of Empowerment, 4(2), 83-94.

https://doi.org/10.31258/raje.4.2.83-94

Received: 2021-01-30 Revised: 2021-09-02 Accepted: 2021-09-03

Language: Bahasa Indonesia (id)

Funding: Kementrian Riset, Teknologi dan Perguruan Tinggi, Republik Indonesia

ISSN 2623-1549 (online), 2654-4520 (print)

(c) 2021 Asus Maizar Suryanto Hertika, Mohamad Fadjar, Setya Widi Ayuning Permanasari, \& Bimo Aji Nugroho. Author(s) retain the copyright of article published in this journal, with first publication rights granted to Riau Journal of Empowerment. The article is licenced under Creative Commons Attribution 4.0 International License. This license permits unrestricted use, distribution, and reproduction in any medium, provided the original author and source are credited. 
Keywords: aquaponics; ampeldento; prosperity; narrow land; society; PKK mover team

\section{PENDAHULUAN}

Ampeldento merupakan salah satu desa di Kecamatan Karangploso, Kabupaten Malang, Jawa Timur. Desa Ampeldento tergolong desa dengan luas paling kecil di Kecamatan Karangploso, yaitu sebesar 153 Ha (Badan Pusat Statistik Kabupaten Malang, 2019). Tata guna lahan Desa Ampeldento digunakan sebagai pemukiman sebesar $31 \mathrm{Ha}$, pertanian sebesar $136 \mathrm{Ha}$, perkantoran sebesar 0,0198 Ha, sekolah $0.35 \mathrm{Ha}$ dan tempat pemakaman umum $0.59 \mathrm{Ha}$ (Pemerintah Desa Ampeldento, 2018). Saat ini, perkembangan pembangunan terjadi cukup cepat terutama untuk kegiatan pemukiman dan pariwisata, karena lokasi desa yang berada di antara jalur wisata dan kota wisata. Fenomena tersebut membuat alih fungsi lahan menjadi semakin besar, diimbangi dengan kebutuhan dan pertumbuhan penduduk, sedangkan luas lahan yang ada bersifat tetap (Fattah \& Purnomo, 2018).

Kondisi lahan yang sempit memberikan batas ruang gerak inovasi masyarakat dalam peningkatan perekonomian, terutama ibu rumah tangga berusia 50 tahun yang tergolong dalam cluster non produktif. Produktivitas sangat dipengaruhi oleh umur/usia dimana usia yang tergolong tua cenderung memiliki produkvitias rendah dan fisik yang lemah serta terbatas (Safira \& Nurdiawati, 2020). Untuk memenuhi kebutuhan ekonomi secara mandiri, terbentuklah Tim Penggerak PKK Desa Ampeldento yang beranggotakan ibu-ibu rumah tangga berusia $\geq 50$ tahun. Program pertama yang telah dilaksanakan yaitu arisan rutin dengan tujuan dapat meningkatkan ekonomi masyarakat. Namun, program tersebut tidak bersifat keberlanjutan dan hanya memberikan dampak pada satu orang saja pada sisi finansial. Sesuai dengan karakter ibu-ibu yang didominasi oleh kegiatan sehari-hari berada di rumah, Tim Penggerak PKK Desa Ampeldento berharap bisa mengembangkan suatu kegiatan produktif yang bersifat keberlanjutan, memberikan dampak finansial dan membantu memenuhi kebutuhan gizi sehari-hari seperti menanam dan beternak. Dengan kondisi lahan yang sempit, harapan Tim Penggerak PKK Ampeldento dapat direalisasikan melalui pembuatan akuaponik. Lahan sempit non produktif (pekarangan rumah) dapat dimanfaatkan sebagai lahan budidaya secara akuaponik untuk memproduksi ikan dan sayur dalam rangka pemenuhan kebutuhan gizi skala rumah tangga dan peningkatan pendapatan masyarakat melalui hasil produksi akuaponik (Bangkit et al, 2017).

Akuaponik merupakan teknologi terintegrasi antara akuakultur dengan hidroponik untuk lahan kritis agar tetap produktif dan menjadi sistem pangan terpadu (Setyono et al, 2019). Tanaman yang dapat dibudidayakan di sistem akuaponik berupa tanaman yang bersifat dapat memanfaatkan zat hara yang ada di air. Sayuran yang cocok dibudidayakan secara akuaponik yaitu kangkung, bayam dan sawi, sedangkan ikan yang cocok dibudidayakan yaitu ikan lele dan nila (Wibowo et al, 2020). Sistem akuaponik memiliki siklus yang terus berputar, sisa kotoran dan pakan ikan akan dimanfaatkan oleh tanaman sebagai nutrisi sehingga air yang kembali ke kolam ikan terfilter dan memperpanjang pergantian air kolam (Farida et al, 2017). Sistem akuaponik dapat memberikan keuntungan finansial dari hasil panen yang dipasarkan maupun untuk memenuhi kebutuhan sehari-hari. Melalui akuaponik yang dikembangkan, Tim Penggerak PKK Desa Ampeldento dapat memanen hasil berupa ikan lele, sayur kangkung dan sawi secara mandiri dan lebih bergizi. 
Kegiatan ini merupakan pengabdian masyarakat kepada ibu-ibu Tim Penggerak PKK Desa Ampeldento yang memiliki harapan bisa tetap produktif di usia $\geq 50$ tahun, mandiri secara ekonomi dan pemenuhan gizi sehari-hari. Sistem akuaponik dapat meningkatkan produktivitas ibu-ibu PKK, menambah penghasilan keluarga dan dapat mencukupi kebutuhan gizi seharihari. Tujuan yang ingin dicapai adalah pemberdayaan ibu-ibu PKK berusia $\geq 50$ tahun untuk pengembangan akuaponik di lahan sempit, meningkatkan gizi keluarga dan meningkatkan kreativitas pembuatan produk olahan hasil akuaponik.

\section{METODE PENERAPAN}

\section{Waktu dan tempat penelitian}

Program pemberdayaan masyarakat melalui pengembangan akuaponik dilaksanakan di Desa Ampeldento, Kecamatan Karangploso, Kabupaten Malang. Daerah percontohan dalam pengembangan program pengabdian masyarakat adalah RW 02 dan RW 06. Program pemberdayaan masyarakat dilakukan selama bulan Maret-September 2019. Mitra program adalah Tim Penggerak PKK Desa Ampeldento. Program yang dikembangkan berupa pemberdayaan terhadap tim penggerak PKK Desa Ampeldento melalui pengembangan sistem akuaponik dengan jenis ikan yaitu lele (Clarias sp.) dan 2 jenis sayur yaitu sawi (Brassica chinensis var. parachinensis) dan kangkung (Ipomoea aquatica).

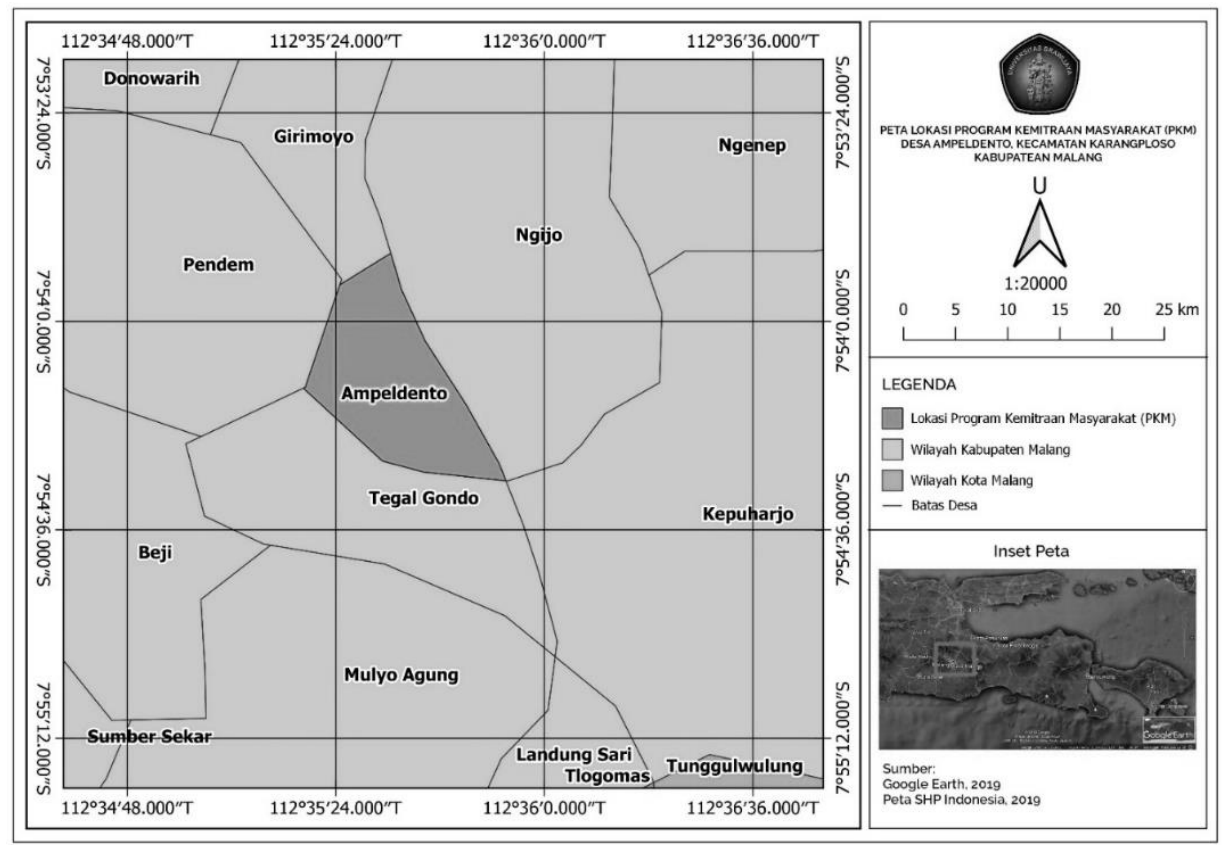

Gambar 1. Peta Lokasi Pemberdayaan Masyarakat di Desa Ampeldento, Karaploso, Kab. Malang

\section{Alur pemberdayaan masyarakat}

Pelaksanaan program pemberdayaan tim penggerak PKK Desa Ampeldento terbagi menjadi 3 tahapan utama, yaitu persiapan, pelaksanaan dan monev (monitoring dan evaluasi). Tahapan persiapan terdiri atas survei lokasi, pendekatan masyarakat sasaran, pengenalan program, serta pembuatan kesepakatan. Tahapan pelaksanaan dilakukan melalui kegiatan penyuluhan dan pelatihan. Kegiatan penyuluhan terdiri atas materi nilai gizi ikan, sayuran bagi keluarga dan pemanfaatan lahan sempit dengan sistem akuaponik. Kegiatan pelatihan berisi materi 
pemasangan alat komponen akuaponik, cara pemeliharaan akuaponik dan penebaran benih sayuran dan ikan lele. Tahapan monitoring dan evaluasi terdiri atas monev mingguan, monev internal (LPPM UB) dan monev eksternal (Kemenristekdikti).

\section{Persiapan pemberdayaan masyarakat}

Kegiatan pemberdayaan diawali dengan persiapan yang terdiri atas survei lokasi, pendekatan masyarakat sasaran, pengenalan program dan pembuatan kesepakatan. Survei lokasi dilakukan dengan melihat kondisi masyarakat dan medan lokasi yang akan dijadikan lokasi percontohan pengembangan akuaponik. Pendekatan masyarakat sasaran dilakukan untuk mengetahui masalah-masalah yang dihadapi masyarakat secara lebih mendalam. Pendekatan masyarakat sasaran dilakukan dengan melakukan wawancara dan pemberian kuisioner. Wawancara merupakan teknik pengumpulan data melalui tatap muka secara langsung untuk mendapatkan informasi yang lebih mendalam dari responden (Sugiyono, 2015). Kuisioner merupakan teknik pengumpulan data melalui pemberian pertanyaan yang telah dibuat oleh peneliti dan dijawab oleh responden secara tertulis (Pontonusa et al, 2019). Evaluasi pemahaman Tim Penggerak PKK Desa Ampeldento terhadap program pemberdayaan dilakukan melalui pretes sebelum pelaksanaan kegiatan dan post-tes setelah kegiatan dilaksanakan menggunakan tiga pilihan jawaban, yaitu "ya", "tidak”, dan "ragu-ragu” (Astuti \& Mulyono, 2019).

Wawancara dan pemberian kuisioner dilakukan kepada Tim Penggerak PKK Ampeldento RW 02 dan RW 06. Jumlah responden dalam wawancara dan pemberian kuisioner terdiri atas 35 orang dari RW 02 dan 35 orang dari RW 06. Pertanyaan pada kuisioner mencakup pengetahuan masyarakat terkait akuaponik (pengetahuan umum, keuntungan dan minat) dan keaktifan tim penggerak PKK. Pertanyaan pada wawancara mencakup pengetahuan umum seputar akuaponik, masalah-masalah yang dihadapi ibu-ibu tim penggerak PKK, harapan untuk dikembangkannya program yang dapat menunjang produktivitas tim penggerak PKK, dan kendala-kendala selama ingin membuat program pengembangan akuaponik. Pengenalan program dilakukan setelah proses wawancara dan pengisian kuisioner selesai dengan cara pengumpulan tim penggerak PKK di rumah ketua tim penggerak PKK. Kegiatan dilanjutkan dengan penandatanganan kesepakatan dengan ketua tim penggerak PKK, kepala desa, ketua RW 02 dan RW 06.

\section{Peningkatan partisipasi masyarakat}

Metode peningkatan partisipasi masyarakat dilakukan dengan cara sebagai berikut:

1. Masing-masing mitra (kelompok PKK RW-02 dan RW-06) akan aktif menghimbau serta menggerakkan seluruh anggotanya untuk berpartisipasi dalam menghadiri setiap kegiatan sosialisasi oleh tim pengabdian selama kegiatan PKM berlangsung.

2. Mitra akan aktif mengikuti praktek kegiatan dalam pembuatan media sistem budidaya akuaponik dan juga mitra akan aktif dalam kegiatan pelatihan cara penggunaan serta pengelolaan budidaya yang baik dan benar dengan menggunakan media sistem akuaponik.

3. Mitra akan saling bekerja sama serta bergotong-royong dalam menjaga dan mengelola budidaya dengan menggunakan sistem akuaponik tersebut. Mitra juga akan aktif melakukan evaluasi monitoring setiap saat terhadap sistem budidaya akuaponik tersebut dan melakukan pelaporan terhadap Tim pelaksana pengabdian program PKM dalam setiap minggunya. 
4. Mitra akan aktif melakukan pengembangan usaha dengan melakukan penjualan hasil produksi budidaya sistem akuaponik serta mitra akan secara aktif mengembangkan aktivitas usaha melalui sistem akuaponik tersebut kepada anggota ataupun kelompok PKK daerah ataupun desa lain.

\section{Pelatihan serta monitoring dan evaluasi}

Tahapan pelaksanaan dilakukan dengan merakit komponen akuaponik di rumah warga, demoplot bagaimana penumbuhan dan perawatan sistem akuaponik, serta penebaran benih sayuran dan lele bersama tim penggerak PKK. Tahapan monitoring dan evaluasi dilakukan dengan memberikan post-tes dalam bentuk kuisioner dan wawancara dengan daftar pertanyaan yang sama seperti saat pendekatan masyarakat. Pemberian kuisioner dan wawancara dengan pertanyaan yang sama dilakukan untuk mengetahui perkembangan pemahaman masyarakat terhadap akuaponik dan harapan keberlanjutan kegiatan. Monitoring dan evaluasi dilakukan oleh pihak internal (LPPM UB), pihak eksternal (Kemenristekdikti), dan Peneliti. Monitoring tehadap keberhasilan kegiatan dilakukan setiap satu minggu sekali meliputi pemantauan terhadap kemampuan ibu ibu yang tergabung dalam kelompok PKK RW-02 dan RW-06 Desa Ampeldento dalam menerapkan sistem akuaponik secara mandiri. Monitoring terhadap kesungguhan masyarakat dalam menerapkan kegiatan PKM yang telah dilakukan. Monitoring terkait adanya perbaikan gizi dalam hal ini peningkatan konsumsi ikan dan sayuran dan peningkatan ekonomi keluarga setelah diterapkannya kegiatan pada masyarakat melalui kelompok PKK RW-02 dan RW-06 Desa Ampeldento.

\section{HASIL DAN KETERCAPAIAN SASARAN}

\section{Hasil penilaian pengetahuan mitra terhadap akuaponik}

Tabel 1. Rekapitulasi Hasil Pemberian Kuisioner Pre-test terhadap Responden di RW 02 dan RW 06

\begin{tabular}{|c|c|c|c|c|}
\hline No & Deskripsi & $\mathrm{Ya}(\%)$ & $\begin{array}{c}\text { Tidak } \\
(\%)\end{array}$ & $\begin{array}{c}\text { Ragu-Ragu } \\
(\%)\end{array}$ \\
\hline 1 & $\begin{array}{l}\text { Responden yang berpendapat bahwa Kelompok PKK } \\
\text { Aktif }\end{array}$ & 60 & 15 & 25 \\
\hline 2 & Responden yang mengenal akuaponik & 10 & 70 & 20 \\
\hline 3 & Responden yang tertarik dengan akuaponik & 50 & 20 & 30 \\
\hline 4 & $\begin{array}{l}\text { Responden yang ingin mengembangkan akuaponik } \\
\text { secara mandiri }\end{array}$ & 40 & 25 & 35 \\
\hline 5 & $\begin{array}{l}\text { Responden yang berpendapat bahwa akuaponik dapat } \\
\text { meningkatkan kesejahteraan }\end{array}$ & 30 & 25 & 45 \\
\hline
\end{tabular}

Tabel 2. Rekapitulasi Hasil Pemberian Kuisioner Post-test terhadap Responden di RW 02 dan RW 06

\begin{tabular}{llccc}
\hline No & \multicolumn{1}{c}{ Deskripsi } & Ya (\%) & $\begin{array}{c}\text { Tidak } \\
(\boldsymbol{\%})\end{array}$ & $\begin{array}{c}\text { Ragu-Ragu } \\
(\boldsymbol{\%})\end{array}$ \\
\hline 1 & Responden yang berpendapat bahwa Kelompok PKK & & & \\
& Aktif & 85 & 5 & 10 \\
2 & Responden yang mengenal akuaponik & 90 & 5 & 5 \\
3 & Responden yang tertarik dengan akuaponik & 95 & 0 & 5
\end{tabular}


4 Responden yang ingin mengembangkan akuaponik secara mandiri setelah dilakukan demoplot akuaponik

5 Responden yang berpendapat bahwa akuaponik dapat meningkatkan kesejahteraan

70

10

20

95

0

5

Hasil wawancara dan pemberian kuisioner kepada masyarakat pada awal pendekatan masyarakat sasaran menunjukkan bahwa sebagian besar masyarakat belum mengenal akuaponik dan masih ragu-ragu dalam mengembangkan akuaponik secara mandiri. Keraguan masyarakat dalam pengembangan akuaponik dikarenakan faktor ekonomi dan belum mengenalnya masyarakat dengan akuaponik. Persepsi responden terhadap akuaponik adalah mahal dan susah dalam penerapannya. Saat dilakukan diskusi, responden menginginkan adanya pelatihan dan bantuan pengembangan akuaponik untuk menambah produktivitas ibuibu PKK dan memberikan pengetahuan lebih terkait akuaponik. Lahan untuk pengembangan produktivitas ibu-ibu PKK hanya dapat dilakukan secara terbatas di pelataran rumah warga, sehingga adanya Teknik pengembangan perikanan dan pertanian di lahan sempit tersebut akan sangat membantu responden. Setelah dilakukan pengenalan program, responden menyatakan ingin membuat berbagai macam produk olahan dari akuaponik yang diterapkan nantinya. Antusiasme masyarakat mulai terlihat saat dilakukan pengenalan progam hingga beberapa ide tercetuskan saat dilakukan diskusi. Rekapitulasi hasil pemberian kuisioner kepada responden dapat dilihat pada Tabel 1 dan Tabel 2.

\section{Pengenalan akuaponik}

Hasil kuisioner terhadap responden yang terdiri atas ibu-ibu tim penggerak PKK RW 02 dan RW 06 didapatkan bahwa 60\% responden menyatakan kegiatan kelompok aktif. Responden rata-rata adalah ibu-ibu PKK yang identik dengan kegiatan sosial, seperti arisan dan kerja bakti. Kegiatan tersebut bersifat rutin, namun bersifat kurang produktif dan tidak sustainable. Hasil kuisioner dengan responden terkait pengetahaun tentang akuaponik didapatkan data bahwa $70 \%$ responden tidak mengenal akuaponik. Kegiatan yang kurang produktif dengan kondisi kelompok yang cenderung aktif dan tidak mengenal akuaponik, maka dikenalkanlah sistem akuaponik kepada ibu-ibu tim penggerak PKK. Pengenalan sistem akuaponik dilakukan dalam bentuk diskusi di rumah ketua tim penggerak PKK Desa Ampeldento. Pengenalan program mencakup pengetahuan umum terkait sistem akuaponik, biaya dalam pembuatan sistem dan keunggulan penggunaan akuaponik. Selama kegiatan pengenalan program, antuasiasme responden sangatlah besar karena perlahan menumbuhkan harapan untuk mengembangkan berbagai macam produk olahan hasil penerapan sistem akuaponik.

Berdasarkan hasil pengenalan program, responden sangat antusias dan terbuka dengan program pemberdayaan yang akan diberikan dan dilanjutkan dengan pemasangan komponen alat akuaponik. Tempat pemeliharaan ikan lele terbuat dari kolam terpal berukuran 1,5 $\mathrm{m} \times 1,5 \mathrm{~m}$ x $1 \mathrm{~m}$ yang rangkanya terbuat dari besi, sehingga lahan yang dipakai tidak akan terlalu luas (Sundari, Jagat, \& Andiono, 2017). Komponen penjernih air yang digunakan yaitu zeolite sebagai filter media tanam. Media tanaman sangat berpengaruh, karena merupakan faktor pendukung dalam penyerapan amonia dari tanaman (Anjani, Kusdarwati, \& Sudarno, 2017). Amonia pada kolam budidaya secara umum berasal dari hewan, tumbuhan, pakan, maupun dari jamur. Amonia terdiri dari amoniak dan amonium. Kadar amonia dipengaruhi oleh suhu dan pH (Gumelar, Nurruhwati, Sunarto, \& Zahidah, 2017). 


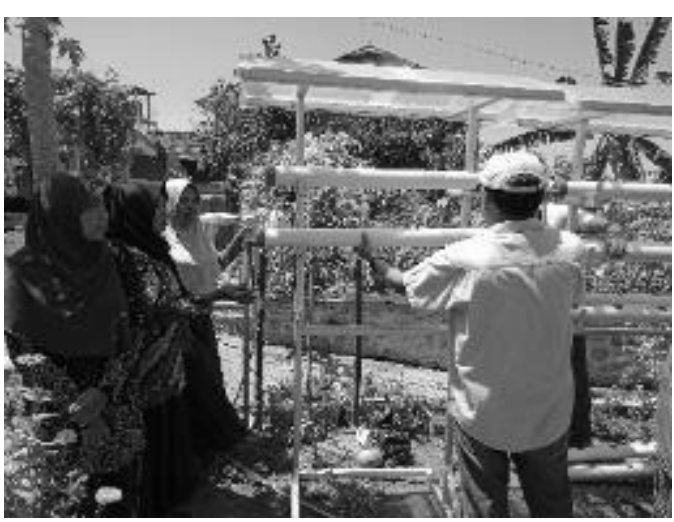

(a)

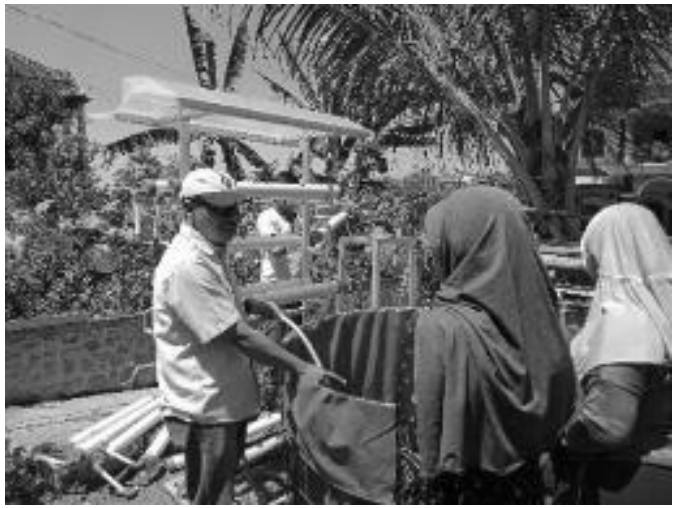

(b)

Gambar 2. Pelatihan pemasangan alat akuaponik (a) dan materi perawatan media akuaponik (b) (Sumber: Dokumentasi Pribadi, 2019)

Pelatihan pemasangan komponen alat akuaponik dilakukan pada rumah ketua tim penggerak PKK sebagai sampel, tepatnya di wilayah RW 02 dan RW 06. Pelatihan dimulai dengan pengenalan komponen alat-alat dan dilanjutkan langsung dengan pemasangan alat. Pelatihan ditekankan pada peningkatan partisipasi aktif ibu-ibu PKK dan memahami proses pembuatan media akuaponik sehingga dapat bersifat sustainable. Selama pemasangan, responden juga diberikan materi terkait perawatan dari media akuaponik tersebut agar ketika program selesai, responden dapat mengembangkannya secara mandiri.

Penebaran benih ikan dan tanaman dilakukan pasca pemasangan komponen alat akuaponik. Untuk budidaya ikan yang paling bagus untuk menunjang akuaponik adalah budidaya ikan lele, sebab lele menghasilkan feses ikan yang lebih banyak dibandingkan jenis ikan lainnya. Lele juga termasuk ikan yang konsumsi pakannya tinggi. Dengan adanya konsumsi pakan yang tinggi, otomatis akan menghasilkan feses yang banyak pula akibat sisa pakan yang tidak termakan. Banyaknya feses yang dikeluarkan oleh ikan lele dan sisa pakan yang mengendap di kolam menjadikan pertumbuhan tanaman menjadi sangat cepat. Jenis tanaman yang biasa dibudidayakan umumnya adalah tanaman sayuran yang bisa dipanen daunnya dan memiliki nilai ekonomis seperti kangkung dan sawi.

\section{Penyuluhan dan demoplot akuaponik}

Masih 50\% responden yang memiliki minat terhadap sistem akuaponik dan 35\% responden masih ragu-ragu untuk mengembangkan akuaponik secara mandiri. Berdasarkan hasil pemberian kuisioner tersebut, maka dilakukan penyuluhan dan demoplot akuaponik agar dapat meningkatkan minat responden terhadap pengembangan akuaponik dan pengetahuan responden terkait gizi ikan beserta sayuran terhadap keluarga. Penyuluhan dan demoplot dilakukan di rumah ketua tim penggerak PKK wilayah RW 06 dengan materi pengetahuan umum akuaponik, cara menyemai tumbuhan akuaponik, penebaran bibit lele, dan penjelasan terkait keuntungan membuat akuaponik. Materi yang disampaikan disesuaikan dengan hasil wawancara dan kuisioner yang sudah diberikan pada saat pengenalan program. Penyuluhan dilakukan dengan metode diskusi dua arah, yaitu pihak fasilitator menyampaikan materi sebagai pemantik yang dilanjutkan dengan tanya jawab antara pemateri dengan peserta. 

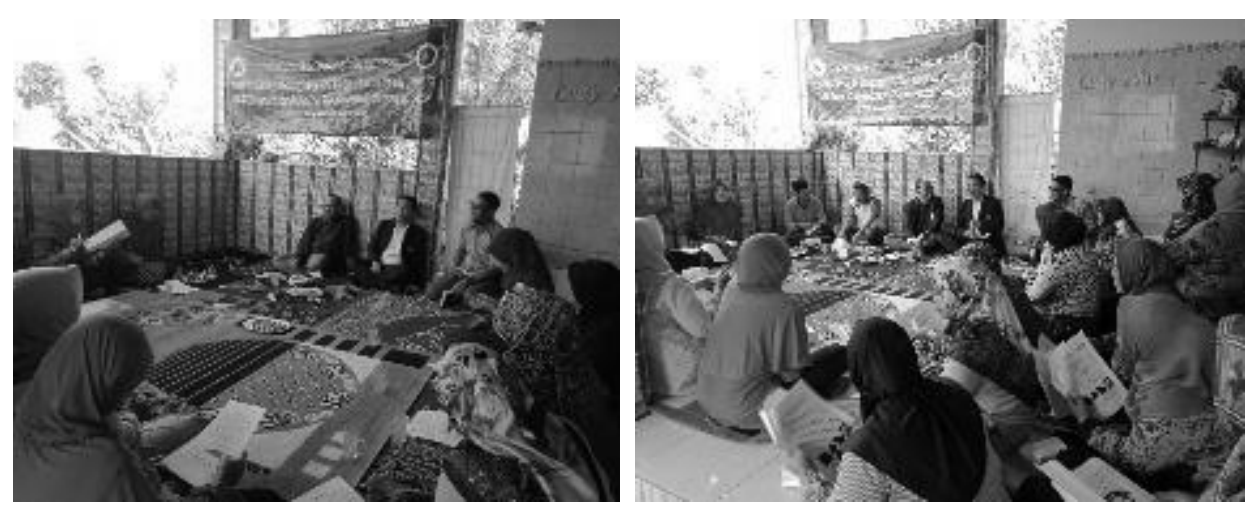

Gambar 3. Penyuluhan dan demoplot akuaponik bersama Tim Penggerak PKK Desa Ampeldento (Sumber: Dokumentasi Pribadi, 2019)

Antusiasme dan rasa ingin tahu ibu-ibu tim penggerak PKK sangat tinggi. keaktivan dan rasa ingin tahu ibu-ibu terkait akuaponik terlihat saat proses diskusi berlangsung, 70\% peserta bertanya seputar sistem akuaponik. Ibu-ibu tim penggerak PKK semakin yakin dalam mengembangkan sistem akuaponik secara mandiri di rumah masing-masing. Hal ini dibuktikan dengan peningkatan keyakinan responden dalam mengembangkan sistem akuaponik sebesar 30\%. Saat dilakukan pengenalan program, $40 \%$ responden berkeinginan mengembangkan akuaponik secara mandiri, 35\% merasa ragu-ragu dan 25\% tidak ingin mengembangkan akuaponik. Setelah dilakukan penyuluhan dan demoplot akuaponik, $70 \%$ responden berkeinginan untuk mengembangkan sistem akuaponik, $20 \%$ merasa ragu-ragu dan $10 \%$ masih tetap tidak berkeinginan mengembangkan sistem akuaponik.

Semakin tingginya tingkat keinginan responden terhadap pengembangan akuaponik secara mandiri dipengaruhi oleh keunggulan akuaponik yang dipaparkan oleh pemateri selama penyuluhan berlangsung serta demoplot akuaponik. Beberapa hal yang disampaikan ke masyarakat bahwa budidaya sistem akuaponik memberikan keuntungan yaitu; memanfaatkan lahan sempit sehingga cocok untuk kegiatan urban farming, tanaman tidak membutuhkan pupuk kimiawi, air tetap terjaga kualitasnya karena melalui sistem filtrasi hidroponik tanaman yg ditanam. Dari hasil kegiatan responden kelompok PKK menyatakan bahwa akuaponik merupakan sistem yang cukup mudah dikembangkan di lahan sempit. Sistem akuaponik membuat responden tidak perlu melakukan penyiraman tanaman setiap hari dan air dapat tersirkulasi secara otomatis. Menurut (Rakhman, Lanya, Rosadi, \& Kadir, 2015) Akuaponik memanfaatkan feses dan ammonia menjadi nitrit dan nitrat sebagai nutrisi bagi tanaman, sehingga wajar jika tanaman tumbuh dengan cepat. Lebih lanjut menurut (Sastro, 2015) Hampir semua jenis budidaya ikan seperti lele, gurami, nila, koi, emas, bawal, mujair, udang galah dan jenis ikan lainnya dapat dimanfaatkan untuk akuaponik. Sedangkan jenis tanaman yang biasa dibudidayakan menurut (Samsugi \& Burlian, 2019) umumnya adalah tanaman sayuran yang bisa dipanen daunnya dan memiliki nilai ekonomis seperti selada, sawi, caisim, kangkung, mentimun, tomat dan paprika.

\section{Akuaponik meningkatkan kesejahteraan masyarakat}

Aquaponik merupakan sebuah alternatif menanam tanaman dan memelihara ikan dalam satu wadah (Handayani, 2018). Akuaponik yang cukup sederhana dapat meningkatkan kesejahteraan masyarakat melalui hasil atau output yang didapat. Berdasarkan pada perhitungan yang telah dilakukan, 1 akuaponik dapat dibudidayakan ikan lele sebanyak 1.875 ekor dengan Survival rate (SR) yaitu 80\%, maka hasil panen didapatkan 1.500 ekor. Pada 
sayurannya sendiri dapat dipanen sebanyak 8-10 kali dalam 1 siklus, sehingga keuntungan bersih yang didapatkan adalah Rp. 550.000. Hasil panen yang didapat cukup menguntungkan sehingga dapat meningkatkan kesejahteraan ekonomi masyarakat Desa Ampeldento.

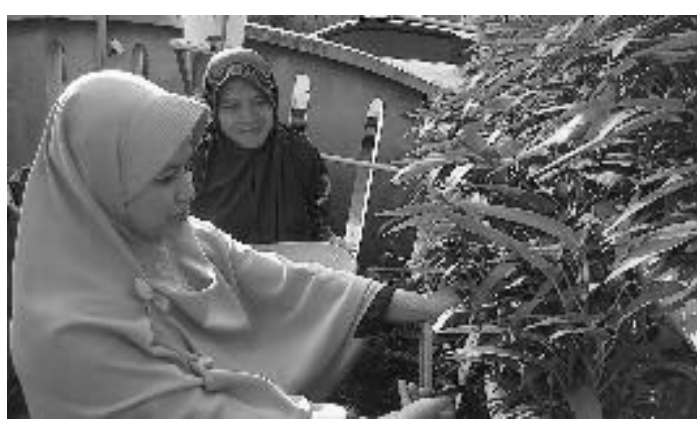

(a)

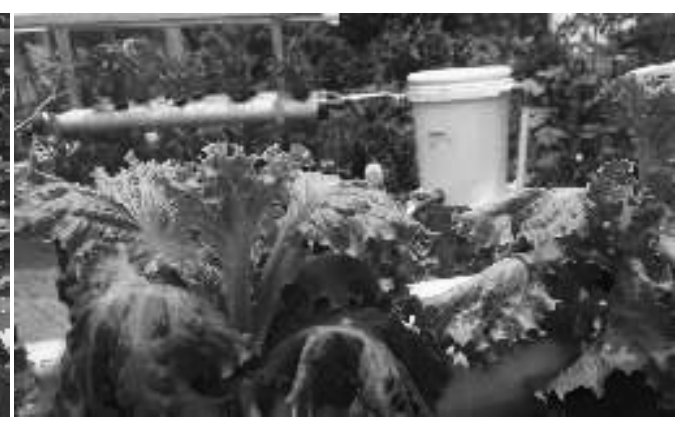

(b)

Gambar 4. Panen Sayuran Hasil Akuaponik Kangkung (a) dan Sawi (b) (Sumber: dokumentasi pribadi)

Hasil panen akuaponik dapat meningkatkan kualitas sayur yang dikonsumsi masyarakat. Berdasarkan hasil wawancara yang telah dilakukan setelah dilakukan pengembangan sistem akuaponik, responden menyatakan bahwa sayur yang dihasilkan lebih cepat tumbuh, enak, hijau, bergizi dan besar. Kualitas sayur yang lebih tinggi dari hasil panen sistem akuaponik membuat semakin tingginya keyakinan masyarakat untuk mengembangkan sistem tersebut. Responden juga menyatakan bahwa dengan adanya sistem akuaponik, maka kebutuhan pangan dan gizi keluarga akan tercukupi secara mandiri.

Berdasarkan hasil panen yang dapat memberikan dampak positif secara ekonomi dan pribadi, masyarakat semakin yakin bahwa akuaponik dapat meningkatkan kesejahteraan masyarakat. Tingkat keyakinan masyarakat tersebut meningkat sebesar $50 \%$ dari saat sebelum masyarakat mengenal akuaponik. Saat pengenalan program, $45 \%$ responden masih merasa ragu-ragu apabila akuaponik dapat meningkatkan kesejahteraan masyarakat, 30\% merasa yakin dan $25 \%$ merasa tidak yakin. Namun, setelah melihat hasil panen sayuran dan ikan yang cukup cepat, 95\% responden merasa yakin bahwa akuaponik dapat meningkatkan kesejahteraan masyarakat. Hasil panen yang sangat baik memberikan peningkatkan kepercayaan masyarakat terhadap pengembangan akuaponik dan diversifikasi produk pangan akuaponik. Berdasarkan kegiatan monitoring dan evaluasi yang dilakukan didapatkan tingkat respon kelompok PKK sangat tinggi hal ini dibuktikan dengan 5 orang anggota PKK yang menerapkan secara mandiri sistem akuponik di pekarangan rumahnya. Hal ini mendorong tim pengabdian untuk berinisiatif melakukan pembinaan lanjutan kaitannya dengan pengolahan produk akuaponik dan pemasaran jika skala produksi yang dihasilkan semakin meningkat.

\section{Monitoring dan evaluasi}

Monitoring dan evaluasi (Monev) dalam program ini terbagi menjadi tiga, yaitu monev rutin, monev internal dan monev eksternal. Monitoring dan evaluasi rutin dilakukan selama satu minggu sekali oleh Tim dari Universitas Brawijaya. Monitoring dan evaluasi rutin dilakukan guna mengetahui perkembangan sayuran dan ikan dalam sistem akuaponik masyarakat. Kualitas sayuran dan ikan terus dipantau, lalu setiap kendala yang terjadi dicatat dan dievaluasi untuk dicarikan solusinya bersama dengan masyarakat. Monev rutin dilakukan selama 3 bulan dengan melibatkan mahasiswa PKM (Praktek Kerja Magang), dari kegiatan monev rutin ini 
didapatkan hasil bahwa sayuran yang ditanam melalui sitem akuaponik sangat subur, dan ikan lele yang dipelihara tumbuh sehat. Untuk satu siklus budidaya telah dipanen 3 kali sayuran organik tanpa penggunaan pupuk kimiawi dan pestisida, dan telah dipanen per unit akuaponik sebanyak kurang lebih $70 \mathrm{~kg}$ ikan lele segar.

Kegiatan Monitoring internal dilakukan satu kali bersama dengan reviewer dari LPPM (Lembaga Penelitian dan Pengabdian kepada Masyrakat) UB untuk melihat perkembangan sayuran dan ikan sistem akuaponik yang diterapkembangkan oleh tim pengabdian masyarakat. Pada kegiatan ini juga dilakukan monitoring eksternal dilakukan satu kali bersama dengan reviewer dari Kementrian Riset dan Teknologi, Pendidikan Tinggi (Kemenristekdikti).

Hasil monev secara keseluruhan menunjukkan perkembangan yang cukup memuaskan dimana masyarakat sangat puas dan senang dengan hasil panen akuaponik yang enak, bergizi, cepat tumbuh, besar dan hijau. Berdasarkan hasil monev tersebut didapatkan bahwa 95\% responden yakin akuaponik dapat meningkatkan kesejahteraan dan $70 \%$ ingin mengembangkannya secara mandiri. Masyarakat merasa terbantu dengan adanya program pengabdian masyarakat di tim penggerak PKK Desa Ampeldento. Berawal dari 70\% responden tidak mengetahui terkait akuaponik, saat dilakukan monev pengetahuan masyarakat meningkat menjadi 90\% mengenal akuaponik. Melalui monev tersebut, maka dapat diketahui program telah berjalan dengan lancar dan berhasil membantu masyarakt Desa Ampeldento.

\section{KESIMPULAN}

Tim Penggerak PKK Desa Ampeldento, Kecamatan Karangploso, Kabupaten Malang merasa sangat terbantu dengan adanya program pengabdian masyarakat pengembangan sistem akuaponik di lahan sempit. Melalui kegiatan pengenalan program, penyuluhan dan demoplot yang telah dilakukan, masyrakat menjadi lebih paham terkait akuaponik. Berdasarkan hasil monitoring dan evaluasi, 95\% masyarakat yakin akuaponik dapat meningkatkan kesejahteraan dan $70 \%$ responden ingin mengembangkannya secara mandiri. Kesejahteraan masyarakat meningkat baik secara ekonomi maupun pribadi. Kualitas sayuran dan ikan yang unggul meningkatkan nilai gizi konsumsi makanan sehari-hari keluarga. Melalui program yang diberikan, produktivitas ibu-ibu tim penggerak PKK semakin meningkat dan berkembang cukup pesat, seperti pembuatan diversifikasi produk hasil akuaponik dan pengembangan akuaponik secara mandiri di setiap rumah.

\section{UCAPAN TERIMA KASIH}

Ucapan terima kasih disampaikan kepada tim penggerak PKK Desa Ampeldento, Pak Yon Mulyono, Ibu Rohmawati, Ibu Sukariawati, Dr. Siti Asmaul Mustaniroh, STP., MP dan Dr. NI GST. AG. GDE Eka Martiningsih atas kerjasamanya selama proses pelaksanaan program pengabdian masyarakat. Selanjutnya ucapan trimkasih untuk biaya Direktorat Riset dan Pengabdian Masyarakat (DRPM), Direktorat Jendral Penguatan Riset dan Pengembangan, Kementrian Riset, Teknologi dan Perguruan Tinggi sesuai dengan Kontrak Pelaksanaan Program Pengabdian Masyarakat Nomor : 050/SP2H/PPM/DRPM/2019, tanggal 18 Maret 2019 dan Lembaga Penelitian dan Pengabdian Masyarakan Universitas Brawijaya. 


\section{Daftar Pustaka}

1. Anjani, P. T., Kusdarwati, R., \& Sudarno. (2017). Pengaruh teknologi akuaponik dengan media tanam selada (Lactuca sativa) yang berbeda terhadap pertumbuhan belut (Monopterus albus). Journal of Aquaculture and Fish Health, 6(2), 67-73. http://dx.doi.org/10.20473/jafh.v6i2.11281

2. $\quad$ Astuti, A., \& Mulyono. (2019). Pemberdayaan KWT Desa Kranggan Dalam Budidaya Padi Dengan Metode S.R.I. Untuk Pertanian Sehat. Warta LPM, 22(1), 45-49.

https://doi.org/10.23917/warta.v21i2.7029

3. Badan Pusat Statistik Kabupaten Malang. (2019). Kecamatan Karangploso dalam Angka 2019. Malang: Badan Pusat Statistik Kabupaten Malang.

4. Bangkit, I., Sugandhy, R., \& Indriani, D. (2017). Aplikasi Budidaya Ikan Integratif Dengan Sistem Akuaponik Dalam Pemanfaatan Pelataran Rumah Sebagai Upaya Peningkatan Pendapatan Masyarakat di RW 05 Desa Sayang, Jatinangor-Sumedang. Jurnal Pengabdian Kepada Masyarakat, 1(3), 145 - 149. Available at https://jurnal.unpad.ac.id/pkm/article/view/16383

5. Farida, N. F., Abdullah, S. H., \& Priyati, A. (2017). Analisis Kualitas Air Pada Sistem Pengairan Akuaponik. Jurnal Ilmiah Rekayasa Pertanian dan Biosistem, 5(2), 385-394.

https://doi.org/10.29303/jrpb.v5i2.54

6. Fattah, A. N., \& Purnomo, E. P. (2018). Analisis Kebijakan Alih Fungsi Lahan Pertanian ke Non - Pertanian di Kabupaten Klaten Tahun 2013-2016 (Studi Kasus Kecamatan Ceper Kabupaten Klaten). Jurnal Ilmu Sosial dan Ilmu Politik, 8(1), 113-140. https://doi.org/10.15575/jp.v8i1.2774

7. Gumelar, W. R., Nurruhwati, I., Sunarto, \& Zahidah. (2017). Pengaruh penggunaan tiga varietas tanaman pada sistem akuaponik terhadap konsentrasi total amonia nitrogen media pemeliharaan ikan koi. Jurnal Perikanan Kelautan, 8(2), 36-42. Available at http://jurnal.unpad.ac.id/jpk/article/view/15485

8. Handayani, L. (2018). Pemanfaatan lahan sempit dengansistem budidaya akuaponik. Prosidding Seminar Nasional Hasil Pengabdian, (pp. 118-126). Available at https://eprosiding.umnaw.ac.id/index.php/pengabdian/article/view/52

9. Pemerintah Desa Ampeldento. (2018). Profil Desa Ampeldento. Malang: Pemerintah Desa Ampeldento.

10. Pontonusa, M. L., Rumagit, G. A., \& Kapantow, G. H. (2019). Strategi Pengembangan Ekowisata Hutan Mangrove di Desa Bahoi Kecamatan Likupang Barat Kabupaten Minahasa Utara. Journal of Agribusiness and Rural Development (Jurnal Agribisnis dan Pengembangan Pedesaan), 1(2), 135-146. Available at https://ejournal.unsrat.ac.id/index.php/agrirud/article/view/24455

11. Rakhman, A., Lanya, B., Rosadi, R. B., \& Kadir, M. Z. (2015). Pertumbuhan tanaman sawi menggunakan sistem hidroponik dan akuaponik. Jurnal Teknik Pertanian Lampung, 4(4), 245254.

12. Safira, R. A., \& Nurdiawati, E. (2020). Hubungan Antara Keluhan Kelelahan Subjektif, Umur dan Masa Kerja Terhadap Produktivitas Kerja Pada Pekerja. Faletehan Health Journal, 7(2), 113-118. https://doi.org/10.33746/fhj.v7i02.106

13. Samsugi, S., \& Burlian, A. (2019). Sistem penjadwalan pompa air otomatis pada akuaponik menggunakan mikrokontroler arduino uno R3. PROSIDING SEMNASTEK 2019, 1, pp. 187-197.

14. Sastro, Y. (2015). Akuaponik: budidaya tanaman terintegrasi dengan ikan, permasalahan keharaan dan strategi mengatasinya. Buletin Pertanian Perkotaan, 5(1), 33-42.

15. Setyono, B. D., Marzuki, M., Junaidi, M., Scabra, A. R., \& Azhar, F. (2019). Peningkatan Produktivitas Lahan Kering di Desa Gumantar Melalui Budidaya Ikan Sistem Akuaponik. Jurnal Abdi Insani LPPM Unram, 6(3), 385-395. https://doi.org/10.29303/abdiinsani.v6i3.268

16. Sugiyono. (2015). Metode Penelitian Kuantitatif, Kualitatif, dan R\&D. Bandung: CV. Alfabeta.

17. Sundari, E. M., Jagat, L., \& Andiono. (2017). Metode Aquaponik untuk Mewujudkan Keluarga Mandiri Pangan Masyarakat. Prosiding Seminar Nasional Darmajaya (pp. 26-34). Bandar 
Lampung: LP4M Darmajaya. Available at https://jurnal.darmajaya.ac.id/index.php/PSND/article/view/855

18. Wibowo, R. H., Sipriyadi, Sugianto, N., Sembiring, S. R., Hutasoit, C. M., Serlyani, Y. K., \& Hidayah, T. (2020). Aplikasi Akuaponik Sayur Organik-Ikan Lele dalam Ember (Asoileledamber) di Kota Bengkulu. Jurnal Pengabdian Pada Masyarakat, 5(3), 656-664. https://doi.org/10.30653/002.202053.561 